\title{
Larval anisakids parasitizing the blue whiting, Micromesistius poutassou, from Motril Bay in the Mediterranean region of southern Spain
}

\author{
A. Valero* , J. Martín-Sánchez, E. Reyes-Muelas \\ and F.J. Adroher \\ Departamento de Parasitología, Facultad de Farmacia, \\ Universidad de Granada, E-18071 Granada, Spain
}

\begin{abstract}
A total of 301 blue whiting, Micromesistius poutassou Risso, 1826, ranging in length from 17 to $28 \mathrm{~cm}$, from Motril Bay (Mediterranean coast, south Spain) were examined for anisakid nematodes, as these fish are common items in the Spanish Mediterranean diet. Three anisakid species were morphologically identified with a total prevalence of $10.63 \%$. Anisakis simplex s.l. Rudolphi, 1809 had a prevalence value of $6.65 \%$, compared with $2.66 \%$ for A. physeteris Baylis, 1923 and 2.33\% for Hysterothylacium aduncum Rudolphi, 1802. Variations in prevalence values with season and host size are discussed. Allozyme markers (leucine aminopeptidase-1) were used to identify anisakid nematodes assigned to the A. simplex complex and all examined larvae were found to correspond genetically to A. pegreffii Nascetti et al., 1986.
\end{abstract}

\section{Introduction}

Anisakids are present in many marine teleosts and the consumption of commercial fish, containing third larval stages (L3) of some anisakid species, constitutes a potential risk for public health. With reference to fish infections, a number of authors have studied the role of marine zooplankton in the transmission of anisakids (Køie, 1993a; Køie et al., 1995; Marcogliese, 1995), although fish may also become infected as a result of predation of other fish infected with L3. Experimental studies on the infection of marine and freshwater fish have shown that the larvae reach the body cavity by penetrating the wall of the stomach or pyloric caecum, infect the general body cavity a few hours later and the musculature after a few days (Smith, 1974). In some fish, such as the herring, the number of larvae of Anisakis simplex in the musculature increases after storage (Smith \& Wootten, 1975). However, Wootten \& Smith (1976) and Smith (1984) showed no migration from the viscera into the flesh of blue whiting once the host is dead. The

\footnotetext{
*Fax: +34 958243862

E-mail: fparasi@ucartuja.ugr.es
}

presence of anisakid larvae in Micromesistius poutassou has been previously reported (Wootten \& Smith, 1976; Bussmann \& Ehrich, 1979; Smith, 1984; Petter \& Maillard, 1988; Ruiz-Valero et al., 1992; Køie, 1993b). The aim of this survey was to study anisakid infections of the blue whiting, as this fish is frequently consumed in Spain.

\section{Materials and methods}

A total of 301 blue whiting (Micromesistius poutassou, family Gadidae) from Motril Bay in southern Spain (Mediterranean Sea) were studied from February 1996 to January 1997.

Fish lengths ranged from 17 to $28 \mathrm{~cm}$. Once measurements of total length were made, the fish were dissected, and the free anisakid larvae collected from the body cavity. The viscera, inner organs, and ventral and dorsal musculature were then separately treated with a pepsin$\mathrm{HCl}$ solution $(\mathrm{pH} 2-2.3)$ at $37^{\circ} \mathrm{C}$, for $2-3 \mathrm{~h}$ (modified after McGladdery, 1986). After the larvae were isolated, they were washed with $0.9 \% \mathrm{NaCl}$ solution and examined under a light microscope. Morphological identification of the anisakids was undertaken using features described by Hartwich (1974), Yoshinaga et al. (1987), Petter \& Maillard 
(1988), Berland (1989) and Køie (1993b). The L3 of Anisakis simplex s.l. were preserved at $-70^{\circ} \mathrm{C}$ until required for subsequent experiments. Larvae were analysed by isoenzyme electrophoresis using thick starch gel (Nascetti et al., 1986; Martín-Sánchez et al., 1998) in a continuous buffer system (electrode buffer $\mathrm{pH}$ 8.6: $661 \mathrm{mM}$ Tris, $83 \mathrm{mM}$ citric acid; gel buffer $\mathrm{pH}$ 8.6: $31 \mathrm{mM}$ Tris and $39 \mathrm{mM}$ citric acid). Electrophoretic studies were carried out on single larvae crushed by freeze-thawing in liquid nitrogen and $40 \mu \mathrm{l}$ of $5 \%$ Triton X-100 solution were added. Each gel was stained for leucine aminopeptidase (LAP, EC 3.4.11.1) after Nascetti et al. (1986) and the LAP-1 locus was analysed genetically. For statistical analyses of infection parameters, hypothesis tests of proportions based on the normal distribution by calculating the $Z_{\exp }$ statistics were used (the differences are significant when $\left.Z_{\text {exp }}>1.96\right)$.

\section{Results}

\section{Levels of infection with anisakid larvae}

Thirty two fish of the 301 examined were infected with anisakid larvae. Table 1 shows the infection parameters for the three species found. The total prevalence was $10.63 \%$. The highest value was $6.65 \%$ for Anisakis simplex s.l. (A. pegreffii according to electrophoretic studies) which was significantly higher than $2.66 \%$ for $A$. physeteris $\left(Z_{\text {exp }}=2.32, \quad P=0.02\right)$ and $2.33 \%$ for Hysterothylacium aduncum $\left(Z_{\exp }=2.56, P=0.01\right)$. The last two species were isolated from eight and seven fish, respectively, and one or two larvae per fish were always isolated. Mixed infections by the three species were only found in one fish, with a prevalence value of $0.33 \%$, whereas combined infections by $A$. pegreffii and $H$. aduncum were recorded in two fish, with a prevalence value of $0.66 \%$. All larvae of the three anisakid species were found in the viscera with the exception of one larva of $A$. pegreffii being found in the ventral musculature.

Seasonal changes in the prevalence, abundance and mean intensity of the three species are recorded in table 2, showing minimal values in the autumn for $A$. pegreffii and in the winter for $H$. aduncum and maximal values in the spring for A. physeteris. However, these differences were not statistically significant.

When anisakid infections were related to fish size (table 3), the highest prevalence and abundance by anisakids were found in the largest fish (length $\geqslant 25 \mathrm{~cm}$ ). This difference was only significant when comparing the fish groups with shorter and longer lengths $\left(Z_{\exp }=2.12, P=\right.$ $0.034)$. The differences observed between the prevalence for single species were not significant.

\section{Allozyme identification of Anisakis simplex s.l.}

The 24 larvae morphologically identified as A. simplex s.l. were analysed electrophoretically to the diagnostic locus LAP-1. These larvae showed the same alleles (100 and 102) and similar allelic frequencies (0.859 and 0.141, respectively) found in A. pegreffii for this locus by Nascetti et al. (1986).

Table 1. Prevalence, abundance, and mean intensity of larval anisakids in the blue whiting.

\begin{tabular}{lcrrrc}
\hline Parasite & NIH & $\mathrm{n}$ & $\mathrm{P}$ & $\mathrm{A}$ & $\mathrm{I}(\mathrm{R})$ \\
\hline Anisakids & 32 & 42 & 10.63 & 0.14 & $1.31(1-4)$ \\
Anisakis pegreffii & 20 & 24 & 6.65 & 0.08 & $1.20(1-4)$ \\
A. physeteris & 8 & 10 & 2.66 & 0.03 & $1.25(1-2)$ \\
Hysterothylacium aduncum & 7 & 8 & 2.33 & 0.03 & $1.14(1-2)$ \\
\hline
\end{tabular}

$\mathrm{NIH}$, number of infected hosts; $\mathrm{n}$, number of larval anisakids; $\mathrm{P}$, prevalence; A, abundance; I, mean intensity; R, range.

Table 2. Seasonal variation in the prevalence, abundance, and mean intensity in larval anisakids in the blue whiting.

\begin{tabular}{lccccc}
\hline Parasite & Parameters & Winter & Spring & Summer & Autumn \\
\hline Anisakids & P & 9.47 & 14.04 & 13.70 & 6.58 \\
& $\mathrm{~A}$ & 0.13 & 0.21 & 0.16 & 0.08 \\
Anisakis pegreffii & $\mathrm{I}$ & 1.33 & 1.50 & 1.20 & 1.20 \\
& $\mathrm{P}$ & 6.32 & 8.77 & 9.59 & 2.63 \\
& $\mathrm{~A}$ & 0.09 & 0.09 & 0.11 & 0.03 \\
A. physeteris & $\mathrm{I}$ & 1.50 & 1.00 & 1.14 & 1.00 \\
& $\mathrm{P}$ & 2.11 & 5.26 & 2.74 & 1.32 \\
& $\mathrm{~A}$ & 0.02 & 0.09 & 0.03 & 0.01 \\
Hysterothylacium aduncum & $\mathrm{I}$ & 1.00 & 1.67 & 1.00 & 1.00 \\
& $\mathrm{P}$ & 1.05 & 3.51 & 2.74 & 2.63 \\
& $\mathrm{~A}$ & 0.01 & 0.04 & 0.03 & 0.04 \\
& $\mathrm{I}$ & 1.00 & 1.00 & 1.00 & 1.50 \\
\hline
\end{tabular}

P, prevalence; A, abundance; I, mean intensity. 
Table 3. Variations in the prevalence, abundance, and mean intensity in larval anisakid infection of blue whiting with host length.

\begin{tabular}{llccc}
\hline $\begin{array}{l}\text { Fish length } \\
(\mathrm{N})\end{array}$ & \multicolumn{1}{c}{ Parasite } & Prevalence & Abundance & $\begin{array}{c}\text { Mean } \\
\text { intensity }\end{array}$ \\
\hline $17-18 \mathrm{~cm}$ & Anisakids & 4.16 & 0.04 & 1.00 \\
$(48)$ & Anisakis pegreffii & 2.08 & 0.02 & 1.00 \\
& A. physeteris & 2.08 & 0.02 & 1.00 \\
$19-20 \mathrm{~cm}$ & Hysterothylacium & - & - & - \\
$(52)$ & Anisakids & 11.53 & 0.13 & 1.16 \\
& A. pegreffii & 5.76 & 0.06 & 1.00 \\
& A. physeteris & 1.92 & 0.01 & 1.00 \\
$21-22 \mathrm{~cm}$ & H. aduncum & 3.84 & 0.05 & 1.50 \\
$(64)$ & Anisakids & 7.81 & 0.12 & 1.60 \\
& A. pegreffii & 6.25 & 0.10 & 1.60 \\
$23-24 \mathrm{~cm}$ & A. physeteris & 1.56 & 0.01 & 1.00 \\
$(60)$ & H. aduncum & - & - & - \\
& Anisakids & 10.00 & 0.10 & 1.00 \\
& A. pegreffii & 6.66 & 0.06 & 1.00 \\
$\geqslant 25 \mathrm{~cm}$ & A. physeteris & - & - & - \\
$(77)$ & H. aduncum & 3.33 & 0.03 & 1.00 \\
& Anisakids & 16.88 & 0.24 & 1.46 \\
& A. pegreffii & 10.38 & 0.11 & 1.12 \\
& A. physeteris & 6.49 & 0.07 & 1.20 \\
& H. aduncum & 3.89 & 0.03 & 1.00 \\
\hline
\end{tabular}

$\mathrm{N}$, number of examined hosts.

\section{Discussion}

Three anisakid species, Anisakis pegreffii, A. physeteris and Hysterothylacium aduncum, were identified in the blue whiting collected from Motril Bay in western Mediterranean Sea, off southern Spain.

According to Nascetti et al. (1986) and Mattiucci et al. (1997), A. simplex is a complex of three sibling species, which are reproductively isolated. Of these, $A$. simplex s.s. is mainly found in the Atlantic Ocean whereas A. pegreffii principally inhabits the Mediterranean Sea although specimens of the two forms can coexist in the same area and even in the same host. In the present study, 42 anisakid larvae isolated from the blue whiting were in the third larval stage, 24 of which were morphologically identified as $A$. simplex s.l., and electrophoretically identified as $A$. pegreffii.

The prevalence of anisakids in the blue whiting from Motril Bay is much lower than those (63-100\%) occurring in specimens examined from the Atlantic Ocean (Wootten \& Smith, 1976; Sanmartín et al., 1989; Ruiz-Valero et al., 1992). Moreover, Ruiz-Valero et al. (1992) reported a prevalence of $23.5 \%$ for $A$. simplex s.1. in fish collected from the Spanish Mediterranean coast, while in the present study, this prevalence value was even lower $(6.65 \%$ for A. pegreffii).

In this survey, the prevalence of infection by H. aduncum was $2.33 \%$, whereas in a previous report for fish collected along the Spanish Mediterranean coast no infection by H. aduncum was recorded (Ruiz-Valero et al., 1992). However, the prevalence in blue whiting from the Spanish Atlantic coast was 22.4\% (Ruiz-Valero et al., 1992) and $23.9 \%$ (Sanmartín et al., 1989).

Ruiz-Valero et al. (1992) also reported an increase in the prevalence of $A$. simplex s.l. and $H$. aduncum in blue whiting marketed in Granada during spring and summer. However, in the present study, no significant differences in infections could be attributed to seasonal variation (table 2), presumably due to the low levels of anisakid infection. On the other hand, a higher prevalence and abundance in hosts longer than $25 \mathrm{~cm}$ were observed (table 3). An increase in the prevalence of anisakids in larger blue whiting and other species has been recorded (Bussmann \& Ehrich, 1979; McGladdery \& Burt, 1985; Ruiz-Valero et al., 1992; Adroher et al., 1996), and this could be due to an accumulation of parasites in the host throughout its life (Bussmann \& Ehrich, 1979).

In recent years, several cases of anisakidosis have been reported in Spain and one, at least, in a patient who frequently consumed hake and blue whiting (Clavel et al., 1993). Also, Yagi et al. (1996) described a woman patient with diarrhoea and abdominal pain, which was followed by the expulsion of one adult worm of $H$. aduncum. However, only one $A$. pegreffii larva $(<5 \%$ larvae of all three species) occurred in the fish musculature.

Finally, the low prevalence of anisakids in fish studied in this survey $(10.63 \%)$, especially in the muscle $(0.33 \%)$, and the low mean intensity of infection (1.31) clearly indicate that the risk of contracting anisakidosis from consumption of blue whiting captured from Motril Bay in the southern Spain (western Mediterranean Sea) is very small.

\section{Acknowledgements}

Thanks are due to Dr M. Valderrama from the Department of Statistics and Operations Research (University of Granada) for assistance with statistical analysis of the data. This work was partly funded by the Spanish Grant PB98-1312 from the DGESIC and the Research Groups Grant from Junta de Andalucía.

\section{References}

Adroher, F.J., Valero, A., Ruiz-Valero, J. \& Iglesias, L. (1996) Larval anisakids (Nematoda: Ascaridoidea) in horse 
mackerel (Trachurus trachurus) from the fish market in Granada (Spain). Parasitology Research 82, 253-256.

Berland, B. (1989) Identification of larval nematodes from fish. pp. 16-22 in Möller, H. (Ed.) Nematode problems in North Atlantic fish. Report from a workshop in Kiel, 3-4 April 1989. International Council for the Exploration of the Sea CM/F6.

Bussmann, B. \& Ehrich, S. (1979) Investigations on infestation of blue whiting (Micromesistius poutassou) with larval Anisakis sp. (Nematoda: Ascaridida). Archiv für Fischereiwissenschaft 29, 155-165.

Clavel, A., Delgado, B., Sánchez-Acedo, C., Carbonell, E., Castillo, J., Ramírez, J., Quílez, J., Gómez-Lus, R. \& Kagei, N. (1993) A live Anisakis physeteris larva found in the abdominal cavity of a woman in Zaragoza, Spain. Japanese Journal of Parasitology 42, 445-448.

Hartwich, G. (1974) Keys to genera of the Ascaridoidea no. 2 in Anderson, R.C., Chabaud, A.G. \& Willmott, S. (Eds) $\mathrm{CIH}$ keys to the nematode parasites of vertebrates. Slough, $\mathrm{CAB}, \mathrm{iv}+15 \mathrm{pp}$.

Køie, M. (1993a) Aspects of the life cycle and morphology of Hysterothylacium aduncum (Rudolphi, 1802) (Nematoda, Ascaridoidea, Anisakidae). Canadian Journal of Zoology 71, 1289-1296.

Køie, M. (1993b) Nematode parasites in teleosts from 0 to 154 $\mathrm{m}$ depth off the Faroe Islands (The North Atlantic). Ophelia 38, 217-243.

Køie, M., Berland, B. \& Burt, M.D.B. (1995) Development to third-stage larvae occurs in the eggs of Anisakis simplex and Pseudoterranova decipiens (Nematoda, Ascaridoidea, Anisakidae). Canadian Journal of Fisheries and Aquatic Sciences 52, 134-139.

Marcogliese, D.J. (1995) The role of zooplankton in the transmission of helminth parasites to fish. Review of Fish Biology and Fisheries 5, 336-371.

Martín-Sánchez, J., Paniagua, I. \& Valero, A. (1998) Contribution to the knowledge of Hysterothylacium aduncum through electrophoresis of the glucose phosphate isomerase and phosphoglucomutase. Parasitology Research 84, 160-163.

Mattiucci, A., Nascetti, G., Cianchi, R., Paggi, L., Arduino, P., Margolis, L., Brattey, J., Webb, S., D'Amelio, S., Orecchia, P. \& Bullini, L. (1997) Genetic and ecological data on the Anisakis simplex complex, with evidence for a new species (Nematoda, Ascaridoidea, Anisakidae). Journal of Parasitology 83, 401-416.

McGladdery, S.E. (1986) Anisakis simplex (Nematoda: Anisakidae) infection of the musculature and body cavity of Atlantic herring (Clupea harengus harengus). Canadian Journal of Fisheries and Aquatic Sciences 43, 1312-1317.

McGladdery, S.E. \& Burt, M.D.B. (1985) Potential of parasites for use as biological indicators of migration, feeding, and spawning behaviour of northwestern Atlantic herring (Clupea harengus). Canadian Journal of Fisheries and Aquatic Sciences 42, 1957-1968.

Nascetti, G., Paggi, L., Orecchia, P., Smith, J.W., Mattiucci, S. \& Bullini, L. (1986) Electrophoretic studies on the Anisakis simplex complex (Ascaridida: Anisakidae) from the Mediterranean and North-East Atlantic. International Journal for Parasitology 16, 633-640.

Petter, A.J. (1969) Enquête sur les nematodes des sardines pêchées dans la région nantaise. Rapport possible avec les granulomes éosinophiles observés chez l'homme dans la région. Annales de Parasitologie Humaine et Comparée 44, 25-35.

Petter, A.J. \& Maillard, C. (1988) Larves d'ascarides parasites de poissons en Méditerranée occidentale. Bulletin du Museum National de Histoire Natural de Paris 4 Ser 10 [A], 347-369.

Ruiz-Valero, J., Valero, A., Adroher, F.J. \& Ortega, J.E. (1992) Presencia de ascáridos en peces comerciales de frecuente consumo en Granada. pp. 335-349 in HernándezRodríguez, S. (Ed.) In memoriam al Profesor Doctor D.F. de P. Martínez Gómez. Universidad de Córdoba, Córdoba, Spain.

Sanmartín, M.L., Quinteiro, P. \& Ubeira, F.M. (1989) Nematode parasites of commercially important fish in NW Spain. Diseases of Aquatic Organisms 7, 75-77.

Smith, J.W. (1974) Experimental transfer of Anisakis sp. larvae (Nematoda: Ascaridida) from one fish host to another. Journal of Helminthology 48, 229-234.

Smith, J.W. (1984) The abundance of Anisakis simplex $\mathrm{L}_{3}$ in the body-cavity and flesh of marine teleosts. International Journal for Parasitology 14, 491-495.

Smith, J.W. \& Wootten, R. (1975) Experimental studies on the migration of Anisakis sp. larvae (Nematoda: Ascaridida) into the flesh of herring, Clupea harengus L. International Journal for Parasitology 5, 133-136.

Wootten, R. \& Smith, J.W. (1976) Observational and experimental studies on larval nematodes in blue whiting from waters to the West of Scotland. International Council for the Exploration of the Sea CM/H35, 1-7.

Yagi, K., Nagasawa, K., Ishikura, H., Nakagawa, A., Sato, N., Kikuchi, K. \& Ishikura, H. (1996) Female worm Hysterothylacium aduncum excreted from human: a case report. Japanese Journal of Parasitology 45, 12-23.

Yoshinaga, T., Ogawa, K. \& Wakabayashi, H. (1987) Experimental life cycle of Hysterothylacium aduncum (Nematoda: Anisakidae) in fresh water. Fish Pathology 22, 243-251.

(Accepted 13 April 2000)

(C) CAB International, 2000 